\title{
Belo Monte: risco ou progresso?
}

Luciana Rodrigues*

\section{Resumo:}

As transformações que ocorrem na modernidade, impulsionadas pela globalização e desenvolvimento industrial e tecnológico produzem riquezas, o que geralmente vem acompanhado da produção de riscos. Essas riquezas trazem consigo ameaças incertas, o que gera inquietação na sociedade. O presente trabalho trata do risco na modernidade reflexiva no caso da construção da usina hidrelétrica de Belo Monte, a qual vem sendo feito sob muita polêmica, principalmente pelos potenciais danos que ameaça causar, já que aquela que será a terceira maior hidrelétrica do mundo e poderá gerar muito mais energia para o país ameaça ter um alto custo financeiro, social e ecológico.

\section{Palavras-chave: Risco, modernidade, Belo Monte}

\begin{abstract}
:
The transformations going on in these modern days, busted by the industrial and technological development due globalization generate wealth growth, which generally comes with increasing risks. This increasing rich's brings uncertain threats, which generate restlessness in society. This present work talks about Belo Monte's hydroelectric construction and the risk installed in the reflexive modernity. Belo Monte has been constructed under high polemic issues, mainly by the high treats it may bring. Being this hydroelectric the third size in the world it could bring much more energy to Brazil, but with the cost of a high financial price, a social and ecologic damage.
\end{abstract}

Key-words: Risc, modernity, Belo Monte

\footnotetext{
* Advogada e bolsista CAPES do Programa de Pós Graduação em Ciências Sociais pela UFSM. Contato: luli_rosa@hotmail.com
}

Latitude, vol. 5, n², pp.111-139, 2011

DOI: https://doi.org/10.28998/2179-5428.20110206 


\section{Belo Monte: risco ou progresso?}

\section{Introdução}

O aumento considerável dos riscos, especialmente os de cunho ambiental, é um ponto chave para o entendimento e transformações que ocorrem na modernidade. Por ser extremamente dinâmica, a sociedade de risco está acabando com a formação de classes e camadas sociais, fazendo com que esse novo estágio de transformação se apresente como algo que destrói e modifica diversas formas sociais, o que Ulrich Beck denomina de modernidade reflexiva.

A "modernização reflexiva" e a globalização, que ganharam impulso especialmente no século XX, trazem consigo grandes mudanças para a sociedade. Essas mudanças ficam muito evidentes no meio ambiente, já que, muitas vezes, a produção de riquezas é acompanhada pela produção de riscos.

Assim, além das fontes de riquezas trazerem consigo ameaças, estas, muitas vezes, são incertas, o que gera inquietações na sociedade. Como exemplo dessa situação, o presente trabalho cita o caso da Usina Hidrelétrica de Belo Monte, a qual vem causando polêmica na medida em que diversos setores da sociedade são contrários à sua construção em razão da falta de conhecimento acerca dos riscos que não estão suficientemente dimensionados, trazendo ainda dúvidas quanto a gestão desses riscos pelo governo, a fim de minimizar ao máximo os efeitos negativos de uma obra desse porte.

\section{I) A SOCIEDADE DE RISCO}

A proliferação dos riscos, especialmente os ambientais e tecnológicos de graves consequências é um ponto crucial para se entender as características, limites e transformações da modernidade. A multiplicação dos riscos é elemento chave para entender essas transformações, pois a sociedade, produtora de riscos, torna-se cada vez mais reflexiva, o que significa dizer que ela se torna um problema para si própria, ficando mais autocrítica e, ao mesmo tempo em que a humanidade põe a si em perigo, reconhece os riscos que produz e reage diante disso (Jacobi, 2005).

A sociedade moderna, em virtude de seu dinamismo, está acabando com suas formações de classe, camadas sociais, ocupação, papéis dos sexos, família nuclear, agricultura, setores empresariais e com os pré-requisitos e formas contínuas do progresso técnico-econômico, fazendo com que esse estágio de transformação e progresso se apresente como um tipo de modernização que destrói e que modifica as diversas formas sociais, o que se denomina para Ulrich Beck, modernização reflexiva (Guerra, 2009). Essa sociedade "reflexiva" vê-se obrigada a confrontar-se com o que ela mesma criou, de modo que os riscos 
constituem-se nas incertezas que terão que enfrentar como algo aceitável pelos empreendimentos e novas tecnologias utilizadas, sendo que não há como medir a amplitude desses riscos incertos, não sabendo quem será por eles atingido.

$\mathrm{Na}$ modernidade tardia, a produção social de riqueza é acompanhada sistematicamente pela produção social de riscos. A transformação da lógica da distribuição de riqueza na sociedade de escassez para a lógica da distribuição dos riscos está ligada a duas condições: Pela autêntica carência material e pela forças produtivas crescentes no processo de modernização que geram riscos e potenciais de ameaça a níveis até então desconhecidos (Beck, 2010).

Assim, o desenvolvimento passa necessariamente por tais riscos, persistindo as tensões entre desenvolvimento e conservação do meio ambiente, sendo o forte viés economicista um dos fatores de questionamento pelas organizações ambientalistas. O conceito de desenvolvimento foi objeto de controvérsias e, até recentemente, a abordagem era de ver o desenvolvimento como sinônimo do crescimento econômico (Jacobi, 2005).

Nesta seara:

O conceito de "indústria" ou de "sociedade de classes" (na mais ampla vertente de Marx e Weber) gira em torno da questão de como a riqueza socialmente produzida pode ser distribuída de forma socialmente desigual e, ao mesmo tempo, "legítima". Isso coincide com o novo paradigma da sociedade de risco, que se apoia fundamentalmente na solução de um problema similar e, no entanto, inteiramente distinto. Como é possível que as ameaças e riscos sistematicamente coproduzidos no processo tardio de modernização sejam evitados, minimizados, dramatizados, canalizados e, quando vindos à luz sob a forma de efeitos colaterais latentes, isolados e redistribuídos de modo tal que não comprometam o processo de modernização e nem as fronteiras do que é (ecológica, medicinal, psicológica ou socialmente) “aceitável”? (Beck, 2010).

Assim, dissemina-se a ideia de que as fontes de riqueza estão "contaminadas" por ameaças "colaterais" (Beck, 2010), posto que cada vez mais o processo de modernização ganha forças destrutivas, já que grandes empreendimentos, grandes descobertas científicas e tecnológicas trazem consigo efeitos inevitáveis, muitas vezes, destrutivos ou desconhecidos, incertos e que 


\section{Belo Monte: risco ou progresso?}

geram dúvidas e inquietações na sociedade.

No caso da hidrelétrica de Belo Monte, as questões que mais preocupam são as mudanças na região da volta grande do Xingu e na vida das pessoas. Terá mudanças nas paisagens, no comportamento das águas do rio e nos igarapés, na fauna e vegetação. Ademais, tem-se a ideia de que a questão de Belo Monte não é local, não dizendo respeito somente a essa barragem.

\section{II) UM BREVE RETROSPECTO DE BELO MONTE}

Belo Monte é uma obra para a construção de uma usina hidrelétrica, planejada, inicialmente, em 1975, por uma consultoria técnica contratada pela Eletrobrás, projeto que, desde o início já teve mais de 15 presidentes diferentes da estatal, 13 diferentes ministros de Minas e Energia e não se sabe quantas trocas de equipe técnica (Valle, 2005), tendo, assim, ocorrido diversas alterações no projeto original, envolvendo um grande número de técnicos e especialistas. Ainda em 1975, foram iniciados os estudos para o aproveitamento hidrelétrico da bacia do Xingu, tendo a Eletronorte contratado a firma CNEC (Consórcio Nacional de Engenheiros Consultores) para pesquisar e indicar o local exato de uma futura hidrelétrica, sendo que em 1979 os estudos declararam a viabilidade de construção de cinco hidrelétricas no Xingu e uma no rio Iriri, dando a elas os seguintes nomes: Kararaô, Babaquara, Ipixuna, Kokraimoro, Jarina e Iriri.

O projeto Kararaô foi a primeira tentativa de barrar as águas do Xingu, tendo despertado uma forte oposição dos povos indígenas e de um amplo grupo de ambientalistas e movimentos sociais, tendo culminado no "Encontro dos Povos Indígenas em Altamira" em fevereiro de 1989, com o objetivo de protestar contra as decisões tomadas na Amazônia sem a participação dos índios e contra a construção do complexo hidrelétrico do Xingu. A grande repercussão do evento suspendeu, por um tempo, com os planos de construção da usina, a primeira tentativa da Eletronorte para o aproveitamento hidrelétrico do rio Xingu, o que só viria a ser discutido novamente durante o apagão no governo Fernando Henrique (GreenPeace, 2011).

Em razão de um verão pouco chuvoso, uma crise de oferta de eletricidade se instalou, quando então Belo Monte foi reapresentada como a "salvação do país" (Sevá Filho, 2005). Assim, em 2001, houve o ajuizamento da primeira Ação Civil Pública pelo Ministério Público Federal de Belém, visando exigir a obrigatoriedade de consultar os indígenas habitantes das áreas que fossem afetadas, bem como a obtenção de autorização do Congresso Nacional, o que é determinado pelo artigo 231 da Constituição Federal.

A decisão judicial decorrente dessa Ação Civil Pública foi no sentido de 
embargar o EIA ${ }^{1}$ (Estudo de Impacto Ambiental) e o processo de licenciamento. Tal decisão, tomada em primeira instância em Belém, no ano de 2001, foi mantida até a última instância, em Brasília. Mais uma vez o projeto Belo Monte foi derrotado, em fins de 2002. Assim, o Governo Federal anuncia a pretensão de modificar os procedimentos para o empreendimento hidrelétrico no rio Xingu. A terceira tentativa de construção da usina hidrelétrica começou nos primeiros meses do governo Lula, quando o senador José Sarney, aliado do governo em exercício, convencia a cúpula federal da importância e oportunidade do projeto Belo Monte.

Em janeiro de 2006, o MPF ajuíza a segunda ação, tentando demonstrar a inconstitucionalidade da falta de oitiva ${ }^{\text {ii }}$ das comunidades indígenas afetadas. A ELETROBRÁS solicitou ao IBAMA a abertura de processo de licenciamento ambiental prévio. Começou, então, a ser feito o Estudo de Impacto Ambiental (EIA). A sentença do processo, em primeira instância, derrubou o entendimento do MPF e dispensou a oitiva dos indígenas atingidos, tendo os estudos sido iniciados. O governo federal, então, se apressa para licenciar a obra, mas começa a fazer o EIA (Estudo de Impacto Ambiental).

A primeira versão do EIA/RIMA é entregue ao IBAMA em 2009, mesmo ano em que a Eletrobrás solicitou a Licença Prévia (LP). O MPF ajuizou uma nova ação em razão de entender que os Estudos de Impacto Ambientais estavam incompletos, sob o argumento de que não seria possível que em dez dias tivessem sido feita a vistoria técnica no local da obra, as reuniões com as comunidades afetadas e a conclusão do termo de referência de uma obra de tal magnitude. O pedido do órgão ministerial foi judicialmente aceito, suspendendo novamente o processo de licenciamento até que os Estudos fossem efetivamente completados.

Já nas audiências públicas, passo seguinte ao EIA, também ocorreram muitos contratempos, tais como alegações de que foram realizadas em apenas três dos onze municípios atingidos pela obra, além de muitas reclamações de pessoas que ficaram de fora em razão de tais eventos terem ocorrido em locais que não comportavam fisicamente a capacidade de pessoas interessadas.

Em fevereiro de 2010 o Ibama concede a Licença Prévia (LP) da hidrelétrica e a ANEEL aprova estudos de viabilidade da UHE Belo Monte.Na mesma época,

\footnotetext{
${ }^{1}$ Estudo de Impacto Ambiental (EIA) é um documento técnico onde se avaliam as consequências para o ambiente decorrentes de um determinado projeto. Nele encontram-se identificados e avaliados de forma técnica os impactos que um determinado projeto poderá causar no ambiente, assim como as medidas mitigadoras. O Relatório de Impacto Ambiental (RIMA) é o relatório que reflete todas as conclusões apresentadas no EIA. Deve ser elaborado de forma objetiva e possível de se compreender, ilustrado por mapas, quadros, gráficos, enfim, por todos os recursos de comunicação visual. (Fonte: Lei nº 7.347/85)
}

Latitude, vol. 5, n², pp.06-21, 2011. 


\section{Belo Monte: risco ou progresso?}

houve a aprovação pelo TCU da previsão de custos para construção da UHE Belo Monte, bem como a aprovação do Edital do Leilão no․ 06/2009, destinado à contratação de energia elétrica proveniente da Usina. Após diversas suspensões das obras pela justiça, recursos foram julgados e as obras novamente liberadas, estando a hidrelétrica em plena execução.

Trata-se de uma questão global, já que ela lida com extinção de espécies, de culturas, não podendo ficar restrito a uma discussão de quantos megawats a usina poderá gerar (Magalhães, 2012). Embora o caso Belo Monte tenha várias implicações as quais estão interligadas, passo a uma descrição separada de cada uma delas exclusivamente para fins de melhor compreensão.

\section{III) OS RISCOS DO EMPREENDIMENTO POR SEUS DIVERSOS ÂNGULOS}

a)Questão econômicalde viabilidade:

Além de ser uma obra extremamente cara, a qual possui um custo estimado² de 26 bilhões de reais e não se saber certamente quem será o responsável pelo financiamento desses custos (o que indica que será financiada por recursos públicos), existe também o problema da viabilidade operacional da hidrelétrica, já que especialistas afirmam que o projeto atual, com apenas uma barragem, não irá gerar energia de maneira satisfatória.

$\mathrm{Na}$ estação seca a vazão pode baixar para menos de $500 \mathrm{~m}^{3}$ de água por segundo. E aí é que surge um aspecto inusitado do projeto: a usina não vai ter um reservatório, o lago artificial formado pelo represamento do rio onde a água fica estocada para consumo da usina, sobretudo na época da estiagem. (Pinto, 2002, p. 43).

Com o valor altíssimo da obra e a dúvida acerca do retorno financeiro, o consórcio construtor recuou, e preferiu somente fazer a obra, mas não ser o concessionário da energia elétrica. O empréstimo que o BNDES deve conceder ao Consórcio Norte Energia pode ser o segundo maior da história da instituição, perdendo somente para o crédito de 25 bilhões liberado para a Petrobrás, que teve contrato de financiamento assinado em julho de 2010 (G1, 2011).

A cifra oficial do custo do investimento nas obras civis,

${ }^{2}$ Fonte: Site da Norte Energia (http://norteenergiasa.com.br/site/2012/08/17/nota-aimprensa/) 
nas máquinas e nos programas complementares da usina Belo Monte é da ordem de 25 bilhões de reais, mas os indicadores usuais na economia internacional das hidrelétricas desse porte podem apontar um custo real de 35 a 40 bilhões de dólares. Este é um dos maiores obstáculos enfrentados atualmente na implantação física da obra: nenhum banco privado nacional ou internacional se dispôs a financiar. O único grande banco que poderia assumir esse risco é o estatal BNDES - que ainda está analisando a viabilidade técnica-econômica do projeto (Sevá, 2011).

Recentemente, a empresa canadense Belo Sun que pretende implantar aquele que dizem ser o maior projeto de exploração de ouro do Brasil na região de Volta Grande do Xingu, decidiu fazer uma proposta de parceria à Norte Energia, consórcio responsável pela usina. A empresa irá propor à Norte Energia a possibilidade de as duas empresas dividirem o investimento necessário para construir a linha de transmissão de energia que ligará as turbinas da hidrelétrica até a cidade de Altamira, no Pará. Todavia, até o momento é incerta a questão de quem vai arcar com esses altíssimos custos, já que o valor da obra tem aumentado cada vez mais e, até o momento, a obra será mesmo feita com recursos públicos.

Ela começou em 19 bilhões, o primeiro orçamento de Belo Monte, e ela está em 28 bilhões, já esta quase passando pra 30. E como você vai amortizar esse investimento se a rentabilidade não existe? Por isso que todas as empreiteiras particulares pularam o muro e passaram a construir, não se interessaram em ser concessionárias, tem uma participação pequena mas quem é o dono, quem banca tudo é Furnas, Chesf, os fundos públicos, fundos estatais, e sobretudo o BNDES. Em 2010, no ultimo ano do Lula, o BNDES além de usar todo o dinheiro que ele tinha, ele ainda recebeu do Tesouro Nacional 200 bilhões de reais pra manter esse esquema de capitalismo nacional, criar a multinacional da carne, como JBS, financiar as hidrelétricas a se manterem... Então, no futuro, quem vai cobrir esse buraco? Essa é a grande questão (Pinto, 2012). 


\section{Belo Monte: risco ou progresso?}

O problema econômico não está somente no custo para que a obra seja feita, mas também no sistema de tributação de energia no Brasil, que faz com que os pagamentos de taxas e impostos sejam realizados no local do consumo da energia, e não no local da produção. Desse modo, se a energia de Belo Monte for utilizada por grandes centros, é lá que será recolhido o ICMS sobre a energia, e não no Pará, onde está o dano ambiental e social.

Além do financiamento alto e incerto da obra, o que preocupa é quanta energia a hidrelétrica efetivamente vai gerar. Isso porque a vazão do rio Xingu varia muito durante o ano, e durante os "meses de inverno", não haverá água suficiente para movimentar as engrenagens das turbinas, as quais necessitam de 700 mil litros de água por segundo, sendo a demanda das 20 máquinas da UHE Belo Monte de 14 milhões de litros de água a cada segundo (Pinto, 2002, p.43). Na visão do Ministério Público Federal Belo Monte é completamente inviável. Para a instituição, o Ibama e a Eletronorte "inventaram" algo chamado trecho de vazão reduzida (TVR), ou seja, um eufemismo para dizer que a hidrelétrica poderia abrir suas comportas para que mais água passasse pela volta grande do Xingu. Todavia, mais água passando, significa menos produção de energia, e o MPF não acredita que o consórcio construtor vá permitir uma maior passagem de água pela volta grande se isso irá reduzir em muito a produção de energia.

$\mathrm{O}$ argumento que consta nas ACPs por parte do MPF é de que o Xingu é um rio que possui uma variação muito grande de vazão durante o ano. Ele sai de mil $\mathrm{m}^{3} / \mathrm{s}$ durante a seca para 25 ou $26 \mathrm{mil} \mathrm{m} / \mathrm{s}$ durante as cheias, repetindo esse ciclo a cada seis meses. O que os procuradores buscam com esse argumento é demonstrar que o rio não tem água suficiente para produzir os $11 \mathrm{mil} \mathrm{MW}$ que o governo diz que a usina terá. Essa será a sua capacidade instalada, que é aquilo que ela produziria se tivesse durante todo o ano $26 \mathrm{mil} \mathrm{m} 3 / \mathrm{s}$ de água. Esse argumento foi aceito pelo governo depois de uns 4 anos do ajuizamento das demandas, tendo o governo reconhecido isso e passado a falar em energia firme, a partir de um livro escrito pelo professor da Unicamp Oswaldo Sevá, engenheiro e sociólogo, o qual dizia que a energia firme produzida seria de $1.500 \mathrm{MW}$, tendo o governo reconhecido que não se trata de $11.000 \mathrm{MW}$, mas de $4.000 \mathrm{MW}$.

Assim, se for como diz o governo, nos meses de seca, a produção de energia será de somente $4,4 \mathrm{mil} \mathrm{MW}$, ou seja, $40 \%$ da capacidade instalada, que é de $11 \mathrm{mil}$ MW, sendo que a atual maior usina do Brasil, a binacional Itaipu tem capacidade de 14 mil MW, e no período da seca tem produção de $61 \%$ de sua capacidade. No entendimento do MPF, essa é a maior prova de que Belo Monte não se sustenta economicamente, porque nenhuma outra hidrelétrica tem uma disparidade tão grande entre a energia firme e a energia instalada.

A Eletronorte já admite que a potência firme da usina será inferior ao patamar internacional de viabilização da 
construção de hidrelétricas, que é de $50 \%$ da capacidade nominal de geração. A potência teórica de Belo Monte, com suas 20 máquinas, é de $11 \mathrm{mil} \mathrm{MW}$, mas a energia firme será de apenas $4,7 \mathrm{MW}$, ou $40 \%$ do máximo que ela será capaz de gerar no pique do verão. Será, por isso, que os técnicos chamam de hidrelétrica a fio d'água, a primeira desse porte na Amazônia, no Brasil e, talvez, no mundo. Toda água que chegar ao simulacro do reservatório, com área de $400 \mathrm{Km}^{2}$, equivalente ao alagamento natural do período de enchente, irá passando pelas turbinas. Para produzir a plena carga, Belo Monte precisará de $14 \mathrm{mil} \mathrm{m}^{3}$ de (14 milhões de litros de água) por segundo. São $700 \mathrm{~m}^{3}$ engolidos por cada das suas 20 gigantescas máquinas, com capacidade individual de $500 \mathrm{MW}$, o suficiente para atender todo o consumo de Belém, com seus 1,2 milhão de habitantes e ainda deixar excedente de $50 \%$. Por falta de água, durante dois meses nenhuma das turbinas da hidrelétrica funcionará. Em outros dois meses, estarão em atividade de duas a quatro máquinas apenas. Só haverá plena carga na usina durante metade do ano. Por isso, seu fator de capacidade será de $43 \%$, já que sua potência firme (a geração média de energia ao longo do ano) será de 4,7 mil MW. A taxa aceitável internacionalmente é de 50\% (Pinto, 2002, p. 14).

A hidreletricidade é a produção de energia elétrica “a partir do aproveitamento do potencial hidráulico de um determinado trecho de um rio, via de regra, assegurado através da construção de uma barragem e da consequente formação de um reservatório" (Bermann, 2007). Nos períodos em que chove mais, com o consequente aumento da vazão da água e maior altura da queda, é possível obter maior quantidade de energia, razão pela qual são feitos reservatórios para regularizar a vazão e garantir disponibilidade energética por mais tempo.

No projeto original de Belo Monte, a represa seria formada com o barramento Kararaô, que ocuparia quando da cheia até uns $1200 \mathrm{~km}^{2}$, afetando toda a faixa ribeirinha no lado de dentro da Volta Grande, até a aldeia Paquiçamba. A represa avançaria ainda dezenas de quilômetros adentro pelos rios afluentes, alagando parte da área urbana de Altamira, onde teriam que ser removidos pontões, palafitas e passarelas (Sevá, 2005). Ocorre que com a redução da área 


\section{Belo Monte: risco ou progresso?}

alagada e com a construção de uma só barragem (e não mais as cinco previstas como viáveis pelo CNEC), para evitar um dano ambiental maior, especialistas alegam que a obra se tornou uma aberração, inviável do ponto de vista hidrelétrico e econômico.

A Eletronorte reduziu a um terço da previsão original o tamanho do reservatório da hidrelétrica de Belo Monte. Ao invés de alagar 1.200 quilômetros quadrados, a barragem passaria a afogar apenas 400 quilômetros quadrados, a partir da calha do rio Xingu. Para uma usina projetada com capacidade nominal de produzir 11 mil megawatts, seria uma façanha. (Pinto, 2002, p.50).

Assim, uma das questões principais gira em torno do custo de fazer uma obra de valor extremamente alto e que não será produtiva com somente um barramento. Daí porque muitos argumentam que Belo Monte será apenas a primeira de muitas outras que serão feitas no Xingu, já que o aproveitamento inicial de Belo Monte será pouco, sendo que os demais barramentos ainda não foram publicizados para evitar audiências públicas com todas as comunidades indígenas do Xingu.

Logo, o problema não é somente a inviabilidade econômica. Ele inclui também o futuro das populações que vivem nas proximidades do rio, pois os especialistas acreditam que não haverá apenas um barramento (posteriormente serão necessários mais) e a futura expansão da obra até locais que abrigam indígenas.

O quebra-cabeça se presta a muita confusão e desinformação. Pelo menos para este nosso livro, fique certo que não acreditamos nunca que "apenas uma" destas duas usinas será feita. Quem o afirma, está deliberadamente escondendo a lógica econômica baseada na contingência hidrológica do rio... ou então, é porque acreditou no que disse o "lobby" atual do projeto Belo Monte (Sevá, 2005).

De acordo com Pinto (2002, p.24), "a conclusão lógica é de que outros barramentos terão que ser feitos a montante para garantir uma vazão útil 
econômica" os quais, se efetivamente vierem a ser construídos, irão aumentar a discussão e problemas sociais que os estudiosos já garantem ser de grande monta. Há que se falar também sobre os problemas sociais, que estão sempre no topo das discussões sobre os impactos da obra.

\section{b) Questão social:}

A questão social tem um peso enorme em Belo Monte. Com a rápida atração de trabalhadores para a obra e a falta do devido acompanhamento de infraestrutura, podem surgir muitos problemas urbanos. De acordo com o EIA/RIMA de Belo Monte, estão previstos para o segundo ano de construção da obra a chegada de mais ou menos 95 mil pessoas, o que fará com que dobre a população do município de Altamira. Conforme relato do Procurador da República Felício Pontes (2012), a população da cidade de Altamira já está em 20 ou 30 mil habitantes a mais, e a infraestrutura da cidade segue a mesma, sem hospitais, sem escola, sem postos de saúde, sem esgoto sanitário.

Quem é que vai pagar segurança pública? Quem é que vai pagar mais professores e mais médicos que serão necessários na região? Não é a Norte Energia, e o pouco que está entregando como medida mitigadora ao governo do estado não dá conta dessa coisa toda. Então, acaba fazendo com que o estado fique mais pobre, o município fique mais pobre, porque não tem uma receita adicional para fazer frente a essa nova demanda, e a população vai ter que se contentar com o serviço pior do que a qualidade que já tinha antes e que já era uma "porcaria" (Pontes, 2012).

Outro problema que o aumento da população causará diz respeito aos empregos. Isso porque a possibilidade de criação de 20 mil empregos diretos ocorrerá somente no segundo e terceiro ano da obra. Fora desses prazos, diminuem as possibilidades de emprego de modo que as pessoas que virão de outros estados (principalmente Maranhão, Piauí e Ceará), provavelmente não retornarão ao seu lugar de origem, pois o fato de terem vindo atrás de empregos na construção civil já é um indício de que não há muitas oportunidades nos locais de onde vem.

Em Altamira, a maior das onze cidades que serão afetadas pelo empreendimento, a rotina já mudou consideravelmente, o que pode ser notado no trânsito mais intenso e no aumento de pessoas em busca de novas oportunidades de trabalho. A cidade que já não tem estrutura nada boa, provavelmente tenha seu 


\section{Belo Monte: risco ou progresso?}

problema agravado pela explosão demográfica que está por vir.

Nos últimos 20 anos Altamira cresceu muito rápido e de forma desordenada, ocupando bairros formados ao longo das margens dos igarapés Altamira e Ambé. Nesses bairros existem muitas casas, pontos de comércio e de serviços como mercearias, venda de hortifrutigranjeiros, peixarias e vendas de gelo para conservação do pescado, bares e serviços de manutenção. Já nas áreas próximas ao igarapé Panelas a ocupação é pequena e algumas pessoas vivem da extração de argila. A maior parte das pessoas que moram nessas áreas vive em condições difíceis, tanto de moradia, quanto sanitária. Não existe rede de esgoto, 18 por cento das casas não têm instalações sanitárias e pouco mais da metade das casas conta com a coleta de lixo feita pela prefeitura. O abastecimento de água é feito por meio de poços em mais de 74 por cento das casas. Esses poços podem estar contaminados porque estão localizados perto das fossas e do lançamento de esgoto diretamente nos cursos d'água. O lixo que é coletado na cidade é despejado em um terreno na margem esquerda da

Transamazônica, no sentido de Itaituba, em área voltada para o igarapé Altamira. Existem pessoas trabalhando, catando materiais plásticos, de alumínio ou ferro. Nos meses de cheia, período conhecido como inverno, os moradores das margens dos igarapés, que têm suas casas inundadas com as cheias no rio Xingu ou na bacia dos próprios igarapés, são abrigados em locais preparados pela prefeitura, que fornece serviços básicos como, por exemplo, água e energia. No início da época de seca, as pessoas voltam para suas casas (RIMA, 2009, p. 72-23).

A preocupação dos proponentes das ACPs é que essas pessoas fiquem no Pará lutando por um pedaço de terras, em um estado em que o conflito no campo é extremamente conhecido, e que os níveis de violência são altíssimos.

Nós já estamos "a duras penas" conseguindo regularizar a situação. A grilagem era muito grande. Nós conseguimos tirar nesses dez anos o cartorário da região, 
que foi processado e perdeu o emprego. Tudo isso foi feito, conseguimos o "Terra Legal" pra lá, pra regularizar a situação fundiária diminuir a tensão de violência no campo... e volta tudo com Belo Monte (Pontes, 2012).

Frequentemente, a expulsão da população que se dá em virtude da construção de hidrelétricas representa a destruição de seus projetos de vida. Uma dificuldade muito grande nessas situações é a de obter efetivamente a compensação passível de assegurar a manutenção das condições de vida anteriores à obra.

O Governo federal estima que 100 mil pessoas migrarão para a região e 32 mil permanecerão lá após as obras. Mas serão necessários apenas 3,5 mil funcionários para operar a usina. Restarão milhares de desempregados, abandonados nas periferias das cidades (MPF, 2011).

Sempre fazendo prevalecer o argumento de que o país necessita de mais energia, e que o desenvolvimento econômico não pode parar, fica omisso o fato de que cerca de vinte mil pessoas serão forçadas a sair de suas casas na parte mais baixa da cidade de Altamira. Em centenas de lotes na área rural e nas margens do Xingu, "inexiste previsão ou qualquer garantia de que essas pessoas sejam realocadas em outros lotes urbanos e/ou assentamentos rurais que favoreçam a retomada de suas atividades econômicas e de seus laços sociais e familiares" (Sevá, 2011).

Não menos importante é a questão dos indígenas. Conforme afirma o MPF, existem duas tribos indígenas que vivem do rio Xingu, no local onde a água vai ficar de $70 \%$ a $90 \%$ menor do que de costume, o que põe em risco a alimentação dessas populações que é basicamente o peixe bem como sua saúde, já que a qualidade da água também irá mudar. Ademais, eles praticam a venda de castanha do Pará, e se deslocam apor meio dos igarapés que se formam nas cheias e que, com a diminuição da vazão da água, provavelmente não existirão mais. Corroborando esses argumentos utilizados pelos Procuradores da República, existem documentos da própria FUNAI reconhecendo que a possibilidade maior é que os indígenas saiam do local.

Assim, além desses problemas da alteração física do local onde vivem essas pessoas, há também a preocupação com a fragmentação cultural, conforme relatou a professora da Universidade Federal do Pará (UFPA) Sônia Magalhães em 


\section{Belo Monte: risco ou progresso?}

entrevista concedida à autora:

A região que a obra afetará congrega, no mínimo, três troncos linguísticos diferentes e várias famílias linguísticas. É uma região que se formou por dois períodos de migração extremamente importantes na história da Amazônia - a primeira metade do século XX e o "boom" do extrativismo e a segunda metade do século $\mathrm{XX}$ com as rodovias, a transamazônica, e as primeiras tentativas de colonização, - sendo isso um caldeirão cultural, social, econômico e político de extrema importância (Magalhães, 2012).

O MPF acredita que se a obra não causar um genocídio propriamente dito, vai causar no mínimo um genocídio cultural, porque a cultura vai mudar completamente a vida das pessoas, já que tem relação com o sagrado, com as festas religiosas, festa da piracema etc, relatando o procurador Felício Pontes (2012) temer que aconteça algo pior, já que conhece bem os indígenas que ali vivem e que dificilmente irão se adaptar a uma nova vida.

Com todos esses problemas que a cidade já apresenta, um crescimento tão rápido e não acompanhado da devida estrutura pode ser um risco para o provimento da condições sociais dignas para a população. Nestas condições, o meio ambiente se torna suscetível a mais devastação e poluição, pela possibilidade de aumento de ocupações irregulares.

\section{c) Questão biológica/ambiental:}

De acordo com Bermann (2007), os principais problemas ambientais em usinas hidrelétricas são a alteração do regime hidrológico (o que prejudica atividades à jusante do reservatório); comprometimento da qualidade das águas, o que dificulta a decomposição dos rejeitos e efluentes; o assoreamento dos reservatórios, submetidos a processos de desmatamento e retirada da mata ciliar. Ocorre também a emissão de gases de efeito estufa, particularmente o metano, decorrente da decomposição da vegetação submersa no reservatório; sobrepressão sobre o solo e subsolo devido ao peso da massa de água represada, em áreas com condições geológicas desagradáveis, provocando sismos induzidos. Problemas de saúde pública, pela formação dos remansos nos reservatórios, com a proliferação de vetores transmissores de doenças endêmicas, e dificuldade de assegurar o uso múltiplo das águas, em razão do caráter de priorização da geração de energia 
elétrica em detrimento do lazer, irrigação, piscicultura, etc, também são resultados de construções de hidrelétricas.

Outra questão que preocupa é a perda da biodiversidade são as espécies lá existentes poderão ser perdidas, desde aquelas já identificadas e catalogadas até aquelas outras que ainda não foram estudadas, e que poderão ser perdidas. O MPF argumenta que em algumas das espécies extintas poderia estar a cura de alguma doenças que traria divisas ao Brasil, talvez muito maiores do que poderá Belo Monte trazer.

O local afetado pela obra possui uma conformação geológica especial que faz com que se tenha um ecossistema único no meio de uma bacia, já que o ecossistema a jusante, a montante e o da volta grande são extremamente diferentes entre si. Assim, tendo a volta grande um ecossistema único, existem várias espécies endêmicas, ou seja, só existem naquele determinado lugar e estão correndo o risco de serem extintas, visto que muitas delas nem ao menos são conhecidas e catalogadas, já que tal região é uma das menos estudadas da Amazônia, de modo que nem ao menos é possível avaliar o tamanho da perda (Magalhães, 2012).

Considerando as especificidades da região Amazônica, o pouco conhecimento que se acumulou sobre as diversas formas de reação da natureza, no que tange ao represamento em suas bacias, pode não ser uma boa alternativa a construção de barragens neste local. O MPF alega que o desconhecimento da região é um problema muito grande, afirmando que quem está pautando essas obras não tem qualquer conhecimento sobre a Amazônia, sobre os povos da floresta, bem como sobre a biodiversidade.

O Amazonas é um desafio que parece ter perdido prioridade e interesse real por detrás do glamour do marketing. As frentes pioneiras avançam abrindo estradas nas terras altas, uma região desconhecida que parece fadada a jamais ser adequadamente revelada porque é destruída antes que o homem possa observá-la e estudá-la em sua condição natural. Um avanço tão selvagem que, em quatro décadas, o índice de destruição da floresta pulou de 1\% para 17\% (Pinto, 2002, p. 116). 


\section{Belo Monte: risco ou progresso?}

Ademais, tem-se a ideia de que a questão de Belo Monte não é local, não dizendo respeito somente a essa barragem. Trata-se de uma questão global, já que ela lida com extinção de espécies, de culturas, não podendo ficar restrito a uma discussão de quantos megawats a usina poderá gerar (Magalhães, 2012).

Já o governo, afirma que o EIA da obra prevê a remoção de $100 \%$ da vegetação dos reservatórios dos canais e $50 \%$ da vegetação do reservatório da calha do rio Xingu, para minimizar o impacto da emissão de gases em razão da decomposição da decomposição da vegetação (EPE, 2011). O conjunto de ações que o EIA propõe para diminuir e compensar as alterações negativas são de responsabilidade do empreendedor, cabendo ao Ibama exigir o cumprimento de todos os Planos, Programas e Projetos que deverão ser realizados pelo empreendedor (RIMA, 2009). Estas ações são as constantes no Plano de Gestão Ambiental abaixo ilustrado:

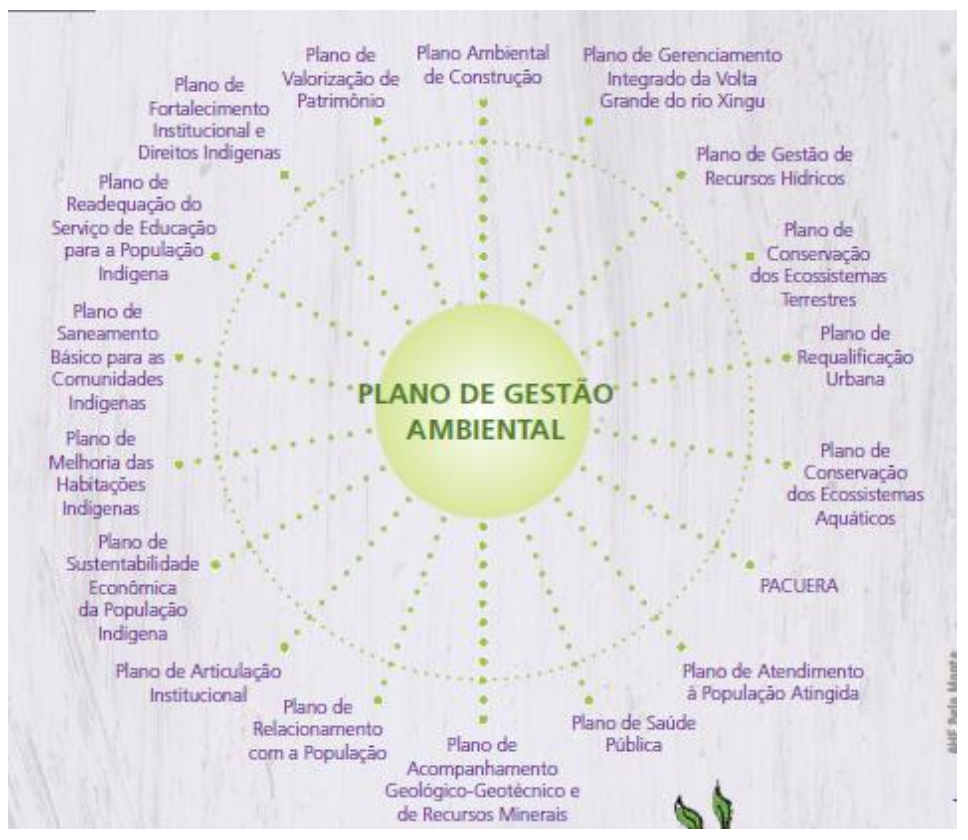

Fonte: RIMA Belo Monte

O MPF afirma que o desmatamento na Amazônia não vai ficar limitado apenas aos $500 \mathrm{Km}^{2}$ que o governo afirma. Isso porque se deve levar em conta o desmatamento indireto que a obra também vai provocar, ou seja, o desmatamento provocado pela pressão humana sobre as áreas adjacentes, o que será ocasionado pela chegada de mais 95 mil pessoas ao local, a área desmatada poderá ser bem 
superior ao estimado.

Segundo dados da própria Norte Energia, se não houver governança, ou seja, se você não tiver o Ibama funcionando, a polícia ambiental funcionando, helicópteros, tudo isso que a gente sabe que é indispensável para que tenha governança o país e que não tem na Amazônia, se isso não tiver funcionando, o desmatamento indireto pode chegar a $5.100 \mathrm{~km}^{2}$ (Pontes, 2012).

O problema é que mesmo que sejam feitos todos esses planos e que efetivamente haja a fiscalização pelo IBAMA, eles somente amenizarão o problema ambiental - pois sabe-se que danos ambientais não são passíveis de compensação. A fiscalização, assim, é outro assunto preocupante, pois essas questões legais e políticas nem sempre funcionam como deveria, já que é muita burocracia para pouca efetividade.

\section{d) Questão política/jurídica:}

A Constituição Federal de 1988, por meio dos artigos 23, I a XII e seu parágrafo único; art. $1^{\circ}$, I a V; art. $3^{\circ}$, I a IV; art. $4^{\circ}$, I a X e art. 225, caput, destacou o direito humano fundamental de todos ao meio ambiente ecologicamente equilibrado, bem de uso comum do povo e essencial à sadia qualidade de vida, impondo-se ao poder público e à coletividade o dever de defendê-lo e preservá-lo para as presentes e futuras gerações. Essa tutela constitucional que impõe ao Poder Público e a toda a coletividade o dever de defender e preservar o meio ambiente já instrumentaliza em seus comandos normativos o princípio da precaução e da prevenção, que consistem, respectivamente, tomar uma decisão mais conservadora quando houver dúvida sobre o potencial deletério de uma determinada ação sobre o meio ambiente e evitar certa atividade danosa quando prevista (Prudente, 2010).

O MPF foi enfático no ajuizamento da $14^{\mathrm{a}} \mathrm{ACP}$, tratando do Direito Intergeracional, sustentando que o que será eliminado com a volta grande do Xingu não poderá ser objeto de estudo das próximas gerações. Embora a legislação estabeleça todas essas regras de preservação, muitos alegam que tais regras foram violadas para a construção de Belo Monte, garantindo o MPF que o governo federal está ignorando a legislação e pesquisas sobre viabilidade econômica, impactos socioambientais e alternativas na geração de energia.

Entre as ilegalidades jurídicas, destaca-se a tentativa da Eletronorte em fazer

Latitude, vol. 5, n², pp.06-21, 2011. 


\section{Belo Monte: risco ou progresso?}

o licenciamento da obra por meio da secretaria de meio ambiente do Pará, enquanto o órgão competente para tal seria o Ibama; As licenças da obra foram concedidas sem o atendimento das condicionantes; O Ibama concedeu uma licença provisória para a instalação do canteiro de obras, licença essa que inexiste na legislação; os estudos de impacto ambiental também não poderiam ter sido contratados sem licitação, em se tratando de uma obra pública; A oitiva das comunidades atingidas - exigida pela Constituição - foi realizada somente em três das onze cidades afetadas pela obra, fato que gerou, inclusive, uma liminar em favor do MPF, mas que em poucos dias acabou sendo derrubada pelo STF; A remoção forçada de indígenas é proibida pela Constituição; Os estudos de impacto ambiental começaram a ser realizados sem o Termo de Referência ${ }^{3}$, e foram entregues incompletos ao Ibama, que os aceitou mesmo assim.

Se você olhar bem os processos judiciais, vai ver que em cada etapa do licenciamento ambiental nós tivemos ilegalidades extremamente graves e, muitas vezes, o próprio Ibama se contradizendo nas questões das condicionantes, onde ele diz que: "Vamos conceder a licença de instalação (LI) depois que as condicionantes da licença prévia (LP) estiverem concluídas. Elas não estavam concluídas - acho que mais da metade não estava - e mesmo assim ele dá a licença prévia, dá uma licença de instalação provisória, o que nem existe na legislação! Por aí se vê que o processo de licenciamento é realmente uma mera formalidade, a decisão já estava tomada de que a obra seria licenciada de qualquer forma e foi (Pontes, 2012).

Com alegações de tantas ilegalidades, especialistas acreditam que a obra do modo como vem sendo executada é uma violação à democracia. De acordo com Magalhães (2012), uma obra do porte de Belo Monte não pode ser feita democraticamente:

\footnotetext{
${ }^{3}$ Termo de Referência - TR tem como objetivo determinar a abrangência, os procedimentos e os critérios gerais para a elaboração do Estudo de Impacto Ambiental (EIA) e o respectivo Relatório de Impacto Ambiental (RIMA), instrumentos de licenciamento ambiental para Aproveitamentos Hidrelétricos (AHE). Devendo ser adequado as características específicas do projeto e do ambiente de sua inserção (Fonte: www.ibama.gov.br).
} 
Participei de uma controvérsia semelhante quando da construção da UHE Tucuruí e havia, o que hoje eu acho que é um equívoco de interpretação, é que a gente acreditava que, pelo menos naquela época, que essa forma autoritária de conduzir o desenvolvimento era inerente aquele momento político de ditadura, e hoje eu estou certa que não. Hoje estou certa que faz parte do desenvolvimento do capitalismo, ele depende de tomadas de posição autoritárias como essa, que só interessam a acumulação capitalista. Então não é possível se construir uma obra como essa, o grau de violência de uma obra como essa, e que a acumulação de capital necessita é tão grande, que não dá pra fazer uma obra dessas democraticamente. Então, a única forma de você implantar uma obra como essa é autoritariamente e, por isso, ela é sempre desastrosa, porque não tem o que você barganhar com a sociedade (Sônia Magalhães, 2012).

Todas essas questões preocupam e geram, além de insegurança jurídica, insegurança quanto ao risco que efetivamente o empreendimento acarreta. Por se tratar de uma obra de tamanha envergadura, não se pode esperar menos dos riscos, os quais necessitam uma séria gestão governamental.

\section{IV) DESENVOLVIMENTO X RISCOS}

Conforme Ulrich Beck (2006), os problemas como os riscos ecológicos não são distribuídos de acordo com a riqueza, meios sociais e estratos, afetando a sociedade como um todo. Os riscos têm um efeito bumerangue, o qual implode o esquema de classes, de modo que tampouco os ricos e poderosos estão seguros diante deles, já que não há como prever quem será afetado por esses riscos.

Assim:

O paradigma da complexidade coloca o desafio do diálogo entre certeza e incerteza, propiciando que os indivíduos vivenciem uma realidade marcada pela indeterminação, a interdependência e a causalidade entre os diferentes processos. Entretanto, isto não deve se transformar numa camisa de força conceitual e metodológica, mas numa articulação entre os processos subjetivos e objetivos que estão presentes na produção de 


\title{
Belo Monte: risco ou progresso?
}

conhecimento e de sentidos (Jacobi, 2005).

No entanto, a capacidade de evitar riscos é altamente dependente de conhecimento e informação, sendo que, aqui, os meios de comunicação entram em jogo dando visibilidade a esses riscos. Desse modo, estando o tema da sustentabilidade em confronto com o paradigma da sociedade de risco, isso implica na necessidade de se multiplicarem as práticas sociais baseadas no fortalecimento do direito ao acesso à informação e à educação em uma perspectiva integradora (Jacobi, 2005).

Nessa seara:

\begin{abstract}
A história da constituição e das transformações do direito moderno tem sido acompanhada por tentativas recorrentes de pensar as suas relações com outra das instituições centrais da modernidade, a ciência. Essas relações têm conhecido diferentes manifestações, que vão da tentativa de construir o próprio direito numa ciência positiva, à imagem das ciências da natureza que emergiram no século XIX, à apropriação, pela ciência, de procedimentos de apresentação e avaliação dos resultados da investigação científica segundo o modelo da avaliação de provas e de deliberação próprios dos tribunais, passando pelas tentativas de utilizar meios de investigação desenvolvidos pelas ciências para reduzir a incerteza e a subjetividade que, alegadamente, afetariam negativamente a qualidade das decisões judiciais e, consequentemente estariam na origem de injustiças e de erros judiciários (Costa e Nunes, 2001).
\end{abstract}

Esse risco de que Beck trata pode ser claramente identificado na construção da Usina Hidrelétrica de Belo Monte. Considerada a maior e mais cara obra do Plano de Aceleração do Crescimento do governo federal (PAC), sua construção está causando grande polêmica, a medida em que a sociedade está preocupada com os riscos, ou seja, os possíveis impactos ambientais e demais problemas que a construção desse grande empreendimento pode causar.

Dentre diversos outros problemas, principalmente de ordem legal, destacam-se a análises de especialistas, que apontam que estudos do projeto supervalorizam os números sobre o volume real de águas do Xingu, que a seca pode atingir populações indígenas e ribeirinhas que dependem diretamente do rio 
Xingu para sobreviver, que o aproveitamento hídrico em terras indígenas não está regulamentado em lei, que não há estudos conclusivos acerca do impacto que o alagamento em parte da cidade de Altamira causará, não se sabendo também a quantidade de pessoas que terão que ser removidas, nem onde serão realocadas.

Além disso, especialistas e estudiosos alegam que o "apodrecimento da vegetação que ficar submersa emitirá grandes quantidades de gás metano, que contribui para o efeito estufa em até vinte e uma vezes mais que o gás carbônico, e que mais de cem mil pessoas migrarão para a região, sendo que trinta e duas mil permanecerão lá após o fim das obras, o que ocasionará milhares de desempregados. Outro grande problema é que as condições que serão criadas no local propiciarão a proliferação de doenças, como a dengue, leishmaniose, doença de Chagas, febre amarela e principalmente a malária, já que essa é a principal doença em importância epidemiológica da região amazônica. Existe também o problema da diminuição dos peixes, já que em alguns trechos do rio o volume de água será extremamente reduzido, de modo que as condicionantes ao projeto impostas pelo Ibama, incluem que sejam feitos projetos para combater as doenças e permitir que as populações que sobrevivam da pesca tenham alternativas.

Como se observa, são muitos os riscos a que, teoricamente, todos estamos expostos. Isso é corroborado pelo ajuizamento da 14a Ação Civil Pública pelo Ministério Público Federal do Pará (MPF) contra a construção de Belo Monte, onde está sendo discutida uma teoria inédita no direito brasileiro, qual seja, o direito de natureza, o qual refere que não somente a população que reside no local está exposta a riscos, mas um incontável número de pessoas, não tendo como prever o alcance desses riscos, já que neste caso, de acordo com todos os documentos técnicos produzidos, seja pelo Instituto Nacional do Meio Ambiente (Ibama), pelas empreiteiras responsáveis pelos estudos, seja pela Fundação Nacional do Índio (Funai), o Ministério Público Federal ou os cientistas que se debruçaram sobre o projeto, Belo Monte vai causar a morte de parte considerável da biodiversidade na região da Volta Grande do Xingu, pois um trecho de $100 \mathrm{~km}$ do rio terá a vazão bastante reduzida para alimentar as turbinas da hidrelétrica. Esse trecho do Xingu é considerado, por decreto do Ministério do Meio Ambiente (Portaria MMA n ${ }^{\circ}$ 9/2007), como de importância biológica extremamente alta, pela presença de populações animais que só existem nessa área, essenciais para a segurança alimentar e para a economia dos povos da região, de modo que a vazão reduzida vai provocar diminuição de lençóis freáticos, extinção de espécies de peixes, aves e quelônios, a provável destruição da floresta aluvial e a explosão do número de insetos vetores de doenças.

Nesse sentido:

Para o MPF, Belo Monte representa a violação não só dos direitos dos índios, ribeirinhos e agricultores que hoje

Latitude, vol. 5, n², pp.06-21, 2011. 


\section{Belo Monte: risco ou progresso?}

vivem no Xingu, mas viola o direito da natureza e o direito das gerações futuras ao desenvolvimento sustentável. "Belo Monte expõe o confronto entre o desenvolvimento a qualquer custo e os princípios do direito ambiental. A solução deve ser sempre em favor do último, diante do bem maior a ser preservado, que é a vida em sentido holístico. Belo Monte compromete, de maneira irreversível, a possibilidade das gerações presentes e futuras de atenderem suas próprias necessidades. Apesar de ser um debate novo no judiciário brasileiro, o direito da natureza e das gerações futuras é objeto de pelo menos 14 convenções e tratados internacionais, todos promulgados pelo Brasil, além de estar presente na Constituição Federal (Solte a Gravata.com, 2011).

$\mathrm{O}$ argumento do direito de natureza passa também pela ideia de que os riscos ambientais não estão limitados a um determinado tempo e espaço, podendo acontecer de seus efeitos poderem ser sentidos com maior incidência ao longo dos anos e alcançar vários locais no mundo, fazendo com que tenhamos, de fato, um problema no plano global (Guerra, 2009). Um bom exemplo disso é a emissão de gases poluentes produtores do efeito estufa, que criam um problema de ordem mundial.

Ao longo dos últimos anos, muitas mudanças ocorreram, o que permite, através da tecnologia da intervenção médica, o planejamento de melhoramentos na limpeza da água, no provimento de alimentação suficiente, o que pode ser melhorado com a ajuda da biomedicina (Rose, 2007), de modo que os riscos embora inevitáveis, possam ser previsíveis. Na perspectiva de Mitchel Dean, em certas circunstâncias, o risco pode ser visto como um continuum e neste sentido nunca desaparece completamente. Assim, ele pode ser minimizado, localizado e evitado, mas nunca pode ser dissipado (Areosa, 2008), razão pela qual a gestão desses riscos é fundamental para evitar maiores danos.

Deste modo:

Com efeito, um significado de governança se destaca nesta seara, qual seja, o que remete à ideia de "gestão", inscrito na crença em um consenso inerente à noção de desenvolvimento sustentável. Este consenso aposta na possível conciliação entre os "interesses" econômicos, ecológicos e sociais, abstraindo dessas dimensões as relações de poder que, de fato, permeiam a dinâmica dos 
processos sociais (Zhouri, 2008).

Em Belo Monte a gestão dos riscos de proliferação de doenças e problema da diminuição de peixes de está sendo feita através de algumas condicionantes ao projeto da hidrelétrica, ou seja, condições impostas pelo Ibama ao consórcio responsável pela obra para que fosse concedida a licença de instalação. Entre algumas das condições, está a reestruturação do atendimento à saúde indígena, e a apresentação de um plano de conservação dos ecossistemas aquáticos, bem como formas de garantia das populações de fauna existentes (Xingu Vivo para Sempre, 2011), o que se constitui em uma forma de biopoder do governo, na tentativa de minimizar os riscos e buscar o desenvolvimento de modo sustentável.

Buscando o desenvolvimento sustentável, em compatibilidade com o progresso cientifico e tecnológico, a precaução apresenta um duplo objetivo: a minimização e gestão dos riscos, bem como a aceitação da inovação. Assim, a lógica precaucionista é inserida num contexto geral de gestão dos riscos, como também na condição de aceitação social dos riscos, cabendo à coletividade distinguir entre as tecnologias que devem ser desenvolvidas e aquelas que devam ser vetadas (Dornelas, 2011).

O risco está em toda parte, fazendo com que prevaleça um grande sentimento de insegurança. Esse sentimento parece ser alimentado pelo desenvolvimento das ciências e das técnicas que são cada vez melhores (Guerra, 2009), pois na medida em que a ciência e tecnologia avançam, trazem consigo o aumento dos riscos, de modo que:

O princípio da precaução pode ser considerado como a forma mais desenvolvida da regra geral, impondo uma obrigação para impedir danos ao meio ambiente. $\mathrm{O}$ princípio da precaução faria parte do direito ambiental internacional, sendo o ponto de partida dos avanços e das formulações do direito ambiental nas relações supranacionais, com base no fato de que a grande maioria das convenções internacionais baseia-se no princípio de que a degradação ambiental deve ser impedida - evitando desta forma poluição ou danos - em vez de se esperar que ela ocorra para então, tentar neutralizar seus efeitos negativos. Desta forma, uma vez adotado, há a necessidade da instalação de um sistema de pesquisa que permita fazer a identificação de riscos para o meio ambiente e para a saúde pública. (Kiss apud Dornelas, 2011).

Latitude, vol. 5, n², pp.06-21, 2011. 


\section{Belo Monte: risco ou progresso?}

Além dos riscos incertos, há grande revolta da sociedade no que tange ao total descaso do governo federal para com a precaução. Isso fica demonstrado pelo fato de o projeto estar sendo implantado sem o cumprimento legal de suas etapas, visto que os estudos de impacto ambiental foram entregues incompletos ao Ibama, e aceitos por este órgão. Esse fato demonstra que a pressa em realizar a obra não permite que sejam tomadas as devidas precauções para reduzir e/ou, ao menos, conhecer possíveis riscos.

A preocupação com os riscos já não mais está centrada em um perigo que era considerado de origem externa, mas com a própria capacidade dos homens, adquirida ao longo da história, de se autotransformar, de autoconfigurar e de autodestruir as condições de vida, criando novos riscos. Desta forma, as fontes dos perigos não estão na ignorância, mas, sim, no saber, não num domínio da natureza de forma deficiente, mas no seu domínio, nem na falta de ação humana, mas precisamente no sistema de decisões e restrições que se estabeleceu na época industrial. A época moderna é ameaça e promessa de liberação de ameaça que ela mesma criou, e, deste modo, os riscos converteram-se no motor da autopolinização da sociedade industrial moderna (Dormelas, 2011).

Desse modo, sendo uma consequência da modernidade que as mudanças que se operam na economia, na política e no comportamento se fazem acompanhar cada vez mais da produção de riscos, inclusive os riscos ambientais, torna-se necessário que tais riscos sejam minimizados o máximo possível, bem como que sejam tomadas medidas de forma a tentar que eles sejam também previsíveis. No caso de Belo Monte, a sociedade está inquieta por não saber o que a construção da hidrelétrica pode ocasionar, estando insegura, ainda, quanto a eventuais precauções que o governo tenha tomado para evitar todos os riscos que uma grande obra como esta envolve, seja pela falta de gestão desses riscos, seja pela inevitabilidade dos mesmos. 


\section{CONSIDERAÇÕES FINAIS}

Como o processo de industrialização está intrinsecamente relacionado ao processo de criação de riscos, o aumento do desenvolvimento científico e industrial são riscos que os indivíduos e a sociedade terão que enfrentar, já que para que o país e a economia se desenvolvam se faz necessária a geração de alguns riscos. Belo Monte está dividindo opiniões e causando grande polêmica, exatamente pela incerteza dos reflexos que a construção poderá trazer, tanto ao ambiente quanto a saúde e bem estar das populações locais.

Com a rapidez com que o projeto está sendo realizado, é possível que medidas de precaução ambiental estejam sendo negligenciadas, pois as licenças para instalação da obra foram concedidas de forma muito ágil, e antes mesmo de terem sido cumpridas as condicionantes impostas pelo Ibama.

Desse modo, o avanço da tecnologia demanda que haja uma gestão dos riscos pelo Estado, a fim de evitar que esses riscos se transformem em problemas concretos, sendo a pesquisa e a ciência um meio de tornar os riscos mais previsíveis, mesmo que sejam inevitáveis. 
Belo Monte: risco ou progresso?

Referências

ANEEL.http://www.aneel.gov.br/aplicacoes/hotsite_beloMonte/index.cfm?p $=8$ ). Acesso em 12/08/2011.

AREOSA, João. O risco no âmbito da teoria social. Disponível em: http://www.aps.pt/vicongresso/pdfs/323.pdf. Acesso em 25/11/2011.

BECK, Ulrich, 1944 - Sociedade de Risco: rumo a uma outra modernidade/ Ulrich Beck : tradução de Sebastião Nascimento - São Paulo: Ed. 34, 2010.

Belo Monte. Entenda a Polêmica. Disponível em: http://www.slideshare.net/ascomprpa/belo-monte-entenda-a-polmica-6861916, acesso em 17/05/2011.

BERMANN, Célio. Impasses e controvérsias da hidreletricidade. Estud. av., São Paulo, v. 21, n. 59, Apr. 2007 . Available from $<$ http://www.scielo.br/scielo.php?script=sci_arttext\&pid=S0103-

40142007000100011\&lng=en\&nrm=iso>. access on 30 July 2012. http://dx.doi.org/10.1590/S0103-40142007000100011.

BLOG Belo Monte Norte Energia. Disponível em: http://www.blogbelomonte.com.br/2011/06/29/plano-de-controle-da-malaria-naarea-de-belo-monte-sera-lancado-sexta-feira/, acesso em 12/11/2011.

COSTA, Suzana; NUNES, João Arriscado. As atribulações da ciência "impura": A harmonização da biologia forense e a diversidade dos sistemas jurídicos. Em: Enteados de Galileu? A semiperiferia no sistema no sistema mundial da ciência. Organizadores: João Arriscado Nunes e Maria Eduarda Gonçalves. Edições Afrontamento, Porto, 2001.

DORNELAS, Henrique Lopes. Sociedade de risco e o princípio da precaução: conceito, finalidade e a questão de sua imperatividade. Revista UNIABEU Belford Roxo V.4 Número 6 Jan. - Abr. 2011. Disponível em: http://www.uniabeu.edu.br/publica/index.php/RU/article/view/118. Acesso em 12/11/2011.

GUERRA, Sidney. A crise ambiental na sociedade de risco. Lex Humana [2175-0947] Ano: 2009 Vol: 1 Nr: 2. Disponível em: 
http://seer.ucp.br/seer/index.php/LexHumana/article/view/27/26. Acesso em 12/11/2011.

GREEN PEACE. A feia história de Belo Monte. Disponível em http://www.greenpeace.org/brasil/pt/Noticias/A-feia-historia-de-Belo-Monte/. Acesso em 08/08/2011.

G1 Belo Monte será a hidrelétrica menos produtiva e mais cara, dizem técnicos. Mariana Oliveira e Marília Juste. Disponível em: fonte: http://g1.globo.com/economia-e-negocios/noticia/2010/04/belo-monte-serahidreletrica-menos-produtiva-e-mais-cara-dizem-tecnicos.html. Acesso em: 08/06/2011.

JACOBI, Pedro Roberto. Educação ambiental: o desafio da construção de um pensamento crítico, complexo e reflexivo. Educ. Pesqui., São Paulo, v. 31, n. 2, Aug. 2005 Available from<http://www.scielo.br/scielo.php?script=sci_arttext\&pid=S151797022005000200007\&lng=en\&nrm=iso>. access on 10 Nov. 2011. http://dx.doi.org/10.1590/S1517-97022005000200007

Ministério Público Federal. Site MPFPA. Disponível em: http://www.prpa.mpf.gov.br/news/2010/noticias/belo-monte-os-problemas-doprojeto-e-a-atuacao-do-mpf. Acesso em: 15/04/2011.

PINTO, Lúcio Flávio. Hidrelétricas na Amazônia: Predestinação, fatalidade ou engodo? Edição Jornal Pessoal: Belém, 2002.

PINTO, Lúcio Flávio. Entrevista concedida à autora em 24/05/2011. Belém PA.

PONTES, Felício. Entrevista concedida à autora em 23/05/2011 no Ministério Público Federal. Belém - PA.

RIMA - Relatório de Aproveitamento Hidrelétrico de Belo Monte. Maio, 2009. Disponível em: www.eletrobras.com. Acesso em 12 de agosto de 2011.

ROSE, N. An emergent form of life? In. ROSE, N. The Politics of life itself: Biomedicine,power and subjectivity in the Twenty-first Century. New Jersey: Princeton University Press, 2007.

SANTOS. Sônia Maria S.B.M. Entrevista realizada pela autora no dia 24/05/2012, na Universidade Federal do Pará, Belém - PA.

Latitude, vol. 5, n², pp.06-21, 2011. 
Belo Monte: risco ou progresso?

SOLTE A GRAVATA.COM. Belo Monte: Primeiro Processo do Judiciário brasileiro que aborda o direito de natureza pede paralisação das obras para evitar remoção de índios. Disponível em: http://solteagravata.com/2011/08/19/belo-monte-primeiro-processo-do-judiciariobrasileiro-que-aborda-o-direito-da-natureza-pede-paralisacao-das-obras-paraevitar-remocao-de-indios/. Acesso em: 13/11/2011.

SANTOS. Sônia Maria S.B.M. Entrevista realizada pela autora no dia 24/05/2012, na Universidade Federal do Pará.

SANTOS, Sônia Maria S.B.M; Hernandez, Francisco del Moral. Painel de Especialistas. Belém, 2009. Disponível em: http://www.prpa.mpf.gov.br/news/2010/noticias/belo-monte-os-problemas-doprojeto-e-a-atuacao-do-mpf. Acesso em 05/05/2011.

SEVÁ Filho. Oswaldo. Aula ministrada no curso de Doutorado em Ciência Sociais da UNICAMP. Em 05/06/2012, Campinas - SP.

SEVÁ Filho, Oswaldo A. Introdução crítica sobre o projeto da hidrelétrica Belo Monte. Texto enviado em 26/11/2011 como contribuição na elaboração de relatórios sobre a situação de direitos humanos no Brasil para instruir o caso brasileiro na Segunda Revisão Periódica Universal (UPR), do Conselho de Direitos Humanos da ONU.

SEVÁ Filho. Oswaldo A. Povos indígenas, as cidades e os beiradeiros do rio Xingu que a empresa de eletricidade insiste em barrar. In: Tenotã Mõ. Alertas sobre as conseqüências dos projetos hidrelétricos no rio Xingu. International Rivers Networks, 2005. Disponível em: http://www.fem.unicamp.br/ seva/TenotaMo_caps1a3_pag92.pdf. Acesso em 05/05/2011.

SEVÁ Filho, Oswaldo A. Tenotã Mõ. Alertas sobre as conseqüências dos projetos hidrelétricos no rio Xingu. International Rivers Networks, 2005. Disponível em: http://www.fem.unicamp.br/ seva/Tenota-Mo_caps1a3_pag92.pdf. Acesso em 05/05/2011.

WIMMER, Jeffrey; QUANDT, Thorstem. Theory Review. Living in the risk society - An interview with Ulrich Beck. Journalism Studies, Vol. 7, nํㅡ, 2006.

Xingu Vivo para Sempre. Condicionantes do projeto Belo Monte. Disponível em: http://www.xinguvivo.org.br/. Acesso em 26/11/2011.

ZHOURI, Andréa. Justiça ambiental, diversidade cultural e accountability: 
desafios para a governança ambiental. Rev. bras. Ci. Soc., $\hat{A}$ São Paulo, $\hat{A}$ v. 23, $\hat{\mathrm{A}} \quad$ n. $\quad 68, \hat{\mathrm{A}}$ Oct. $\hat{\mathrm{A}} \quad 2008 \quad$. $\quad \hat{\mathrm{A}} \quad$ Available from $<$ http://www.scielo.br/scielo.php?script=sci_arttext\&pid=S010269092008000300007\&lng=en\&nrm=iso>. access onÂ 27ÂA Aug.ÂA 2012.Â http://dx.doi.org/10.1590/S0102-69092008000300007.

\footnotetext{
'A crise do apagão foi uma crise nacional ocorrida no Brasil, que afetou o fornecimento e distribuição de energia elétrica. Ocorreu nos dois últimos anos do governo de Fernando Henrique Cardoso, em 1 de julho de 2001 e 27 de setembro de 2002, sendo causado por falta de chuvas, que deixaram várias represas vazias, impossibilitando a geração de energia, e falta de planejamento e investimentos em geração de energia. "Apagão" é um termo que designa interrupções ou falta de energia elétrica freqüentes, como Blecautes (do inglês blackout) de maior duração. No início da crise levantou-se a hipótese de que talvez se tornasse necessário fazer longos cortes forçados de energia elétrica em todo Brasil. Estes cortes forçados, ou blecautes, foram apelidados de "apagões" pela imprensa. Fonte: wikipédia
}

ii $\mathrm{O}$ art. 231, $\S 3^{\circ}$, da Constituição Federal determina que: "O aproveitamento dos recursos hídricos, incluídos os potenciais energéticos, a pesquisa e a lavra das riquezas minerais em terras indígenas só podem ser efetivados com autorização do Congresso Nacional, ouvidas as comunidades afetadas, ficando-lhes assegurada participação nos resultados da lavra, na forma da lei". 